\title{
O DIREITO À CIDADE DA POPULAÇÃO EM SITUAÇÃO DE RUA E OS ESPAÇOS PÚBLICOS
}

\section{ARTIGO ORIGINAL}

SILVA, Mário Augusto Paixão Da ${ }^{1}$

SAULE JUNIOR, Nelson ${ }^{2}$

SILVA, Mário Augusto Paixão Da. SAULE JUNIOR, Nelson. 0 direito à cidade da população em situação de rua e os espaços públicos. Revista Científica Multidisciplinar Núcleo do Conhecimento. Ano 05, Ed. 11, Vol. 10, pp. 42-66. Novembro de 2020. ISSN: 2448-0959, Link de acesso: https://www.nucleodoconhecimento.com.br/lei/situacao-de-rua

\section{RESUMO}

O presente trabalho faz uma análise do direito à cidade e a (não) inserção da população em situação de rua enquanto sujeitos de direitos de usar e fruir adequadamente dos espaços públicos destinados à toda coletividade. O trabalho consiste em pesquisa científica que utiliza materiais históricos e qualitativos, tendo sido efetuada através de consultas em livros, revistas, boletins, sites disponíveis sobre a matéria, além da vivência empírica dos autores com o trabalho de campo. O tema abordado trata do direito à cidade enquanto novo paradigma para enfrentar os principais desafios impostos aos centros urbanos, como acesso aos espaços públicos, redução da pobreza, combate à exclusão social e prevenção de danos ambientais. Nesse contexto, o atendimento à população em situação de rua é questão urgente $\mathrm{e}$

${ }^{1}$ Mestrando em Direito Urbanístico - PUC/SP; especialista em direito ambiental (FMU/SP); especialista em direito eleitoral (IDP/Brasília); especialista em jornalismo científico (LABJOR/UNICAMP); graduado em Direito (FMU/SP); graduado em Comunicação Social - Jornalismo (UFPA).

2 Orientador. Doutor Em Direito Do Estado - PUC/SP. 
necessária para se equalizar o acesso aos espaços públicos nas regiões fortemente afetadas pelo consumo de substâncias entorpecentes e pelo alto adensamento populacional nas vias públicas. $\mathrm{O}$ direito à cidade prevê ações decisivas e políticas públicas específicas em nível nacional, regional e local para atender a esse público que vive em situação de extrema pobreza e vulnerabilidade social. O trabalho demonstra que as ações realizadas pelo Poder Público para mitigação do fenômeno social da população em situação de rua são insuficientes para dar conta do amplo e complexo quadro de carências e necessidades instalado entre aqueles que perderam todos os vínculos com a sociedade, com o mundo do trabalho, com a família e as demais instituições.

Palavras-chaves: Direito à cidade, Espaços públicos, população em situação de rua, Direitos sociais.

\section{DA RELEVÂNCIA DO DIREITO À CIDADE PARA O DESENVOLVIMENTO DE CIDADES HUMANAS E INCLUSIVAS}

Cada vez mais cresce a população vivendo em cidades no mundo, com mais de 3,3 bilhões de pessoas habitando áreas metropolitanas, megacidades, e uma variedade de aglomerados urbanos. No Brasil, a urbanização foi extremamente acelerada. Em menos de 30 anos passamos de um país rural para urbano no século $X X$ com aproximadamente $80 \%$ sendo considerada como população urbana.

Esse processo de urbanização trouxe vários desafios urgentes do nosso tempo, tais como injustiça social, desigualdade social, periferias carentes de infraestrutura, serviços e equipamentos urbanos, segregação entre populações de classes sociais pobres e de alta renda, utilização e ocupação privada de espaços públicos, degradação do meio ambiente, como diminuição de matas e vegetações, poluição de rios e do ar, prevalência de interesses imobiliários sobre os interesses dos moradores.

Nessa década essas preocupações foram tratadas pelos países na Organização das Nações Unidas - ONU, que aprovaram duas agendas globais com vários compromissos e metas para os países desenvolverem cidades mais humanas, 
inclusivas e sustentáveis. Uma delas é a Agenda 2030 que contém 17 Objetivos de Desenvolvimento Sustentável, sendo um deles o de cidades sustentáveis.

A outra é a Nova Agenda Urbana, que contém como visão para o desenvolvimento das cidades o direito à cidade. Vale destacar as mensagens: "não deixe ninguém para trás" (Agenda 2030 - 2015) e "não deixe nenhum lugar para trás" (Declaração do $9^{\circ}$ Fórum Urbano Mundial das Nações Unidas 2018).

No Brasil, desde o ano de 2001, temos uma lei nacional de desenvolvimento urbano chamada Estatuto das Cidades que contém um conjunto de princípios, diretrizes e instrumentos de natureza jurídica e urbanística para enfrentar os problemas que temos em nossas cidades, como a situação das favelas, de áreas de risco, de diminuição de áreas verdes e de espaços públicos, de ausência de participação política dos habitantes. Entre essas diretrizes destacamos o reconhecimento do direito à cidade como um direito dos atuais e futuros habitantes das cidades.

O direito à cidade, portanto, deve ser considerado como um novo paradigma para enfrentar os principais desafios das cidades e dos assentamentos humanos de rápida urbanização, redução da pobreza, exclusão social e risco ambiental, que exigem ações decisivas e novas prioridades políticas nacionais, regionais e governos locais.

O Direito à Cidade é o coração para o desenvolvimento de cidades humanas e inclusivas que tomam todas as medidas necessárias - normativa, urbana, econômica e social para o atendimento das necessidades dos presentes e futuros habitantes, em especial as mulheres, crianças, idosos, grupos em situação de pobreza ou vulnerabilidade, afrodescendentes, indígenas, deslocados, migrantes, mestiços, LGBTQIA+ e com deficiência, entre outros.

\section{A CONCEPÇÃO DO DIREITO À CIDADE NO ESTATUTO DAS CIDADES}

O processo de elaboração do Estatuto das Cidades no Congresso Nacional foi pendurado a mais de uma década (1989-2001) visto que havia uma resistência por 
parte dos grupos políticos conservadores sobre a implementação da política urbana direcionada ao pleno desenvolvimento das funções sociais, da propriedade e da cidade.

Nesse período as discussões e formulações sobre as conexões entre direitos humanos, meio ambiente e sustentabilidade feitas durante as Conferências Globais das Nações Unidas sobre Meio Ambiente e Desenvolvimento (Rio de Janeiro -1992) e sobre Assentamentos Humanos - Habitat II (Istambul -1996), e da Conferência Nacional das Cidades (Brasília-Câmara dos Deputados-1999), bem como a vivência das experiências de gestões participativas em diversos municípios do Brasil por governos do âmbito democrático e popular, foram fundamentais às passagens da visão de direitos urbanos ao direito à cidade que foi integrada no Estatuto das Cidades.

Sob esta evolução, tal direito é classificado como o direito a cidades sustentáveis que aborda a dimensão da sustentabilidade às cidades, devendo ser alcançada por meio de uma política urbana que seja capaz de garantir o seu exercício. Compreende-se, portanto, como seus componentes a terra urbana, à moradia, o saneamento ambiental, à infraestrutura urbana, o transporte e os serviços públicos, o trabalho e o lazer. Deste modo, estes elementos considerados fundamentais a uma vida urbana digna, predominam-se na visão do direito às cidades que foram transportadas da visão dos direitos urbanos.

A gestão democrática das cidades prevista no parágrafo II do artigo 20 do Estatuto das Cidades também é um dos componentes do direito a cidades sustentáveis através de uma interpretação integrada das diretrizes da política urbana estabelecidas nessa legislação. Quanto às pessoas são consideradas titulares do direito a cidades sustentáveis, adota-se a mesma compreensão no direito ao meio ambiente. Esse direito tem como titulares as presentes e futuras gerações. 


\section{OS MORADORES DE RUA COMO TITULARES DO DIREITO À CIDADE}

Um aspecto positivo da evolução sobre os direitos humanos é o da compreensão da pessoa humana abstrata para uma qualificação dessa pessoa em razão da sua condição referente a gerações, gênero, idade, raça, etnia, capacidade civil, penal e política, etc.

Bobbio (1996, p. 68) ao tratar da multiplicação dos direitos considera que esta ocorreu de três maneiras:

a) Em razão do aumento da quantidade de bens considerados merecedores de tutela;

b) Em razão da titularidade de alguns direitos típicos a sujeitos diversos do homem ter sido estendida.

c) Em razão do próprio homem não ser mais considerado como indivíduo genérico de homem em abstrato, mas sim visto na especificidade ou na concreticidade de suas várias maneiras de ser em sociedade, como uma criança, um velho, um doente, etc.

Sobre o direito à cidade é preciso compreender que todas as pessoas que habitam de forma permanente ou transitória as cidades, adotando a compreensão de habitantes são titulares do direito à cidade.

Esse entendimento foi adotado pela Nova Agenda Urbana[3], aprovada na Conferência das Nações Unidas do Habitat III, na cidade de Quito em 2016, que no seu parágrafo 11 versa sobre a visão do direito à cidade nos seguintes termos.

Compartilhamos uma visão de cidades para todos e todas, aludindo ao uso e ao gozo igualitários de cidades e assentamentos humanos, com vistas a promover a inclusão e assegurar que todos os habitantes, das gerações presentes e futuras, sem discriminação de qualquer ordem, possam habitar e produzir cidades e assentamentos humanos justos, seguros, saudáveis, acessíveis física e economicamente, resilientes e sustentáveis para fomentar a prosperidade e a qualidade de vida para todos e todas. Registramos os esforços empenhados por alguns governos nacionais e locais no sentido de integrar esta visão, conhecida 
como "direito à cidade", em suas legislações, declarações políticas e estatutos (NOVA AGENDA URBANA, ONU, 2016, p. 5).

$\mathrm{Na}$ Constituição Federal o artigo 182 definiu como objetivo dessa política o pleno desenvolvimento das funções sociais da cidade e o bem-estar dos seus habitantes, e o Estatuto das Cidades ao tratar do direito a cidades sustentáveis considera que esse direito deve ser garantido para as presentes e futuras gerações.

O município, com base em suas competências constitucionais sobre a política urbana, pode perfeitamente estabelecer que os habitantes que vivem em seu território são os titulares desse direito.

O município de São Paulo, por exemplo, pela sua Lei Orgânica ao tratar da política urbana em seu artigo 148 estabelece como um dos objetivos dessa política garantir o bem-estar de seus habitantes, visando assegurar o uso socialmente justo e ecologicamente equilibrado de seu território; e no seu Plano como objetivo "o pleno desenvolvimento das funções sociais da cidade e o uso socialmente justo e ecologicamente equilibrado e diversificado de seu território, de forma a assegurar o bem-estar e a qualidade de vida de seus habitantes"[4].

Com uma leitura integrada do texto constitucional sobre a política urbana e o conceito jurídico sobre o direito à cidade no Estatuto da Cidade, podemos afirmar que as pessoas titulares desse direito são os habitantes das gerações presentes e futuras das cidades dentre os quais estão incluídos os habitantes na condição de população de rua.

Esses habitantes por estarem na condição de informalidade ou mesmo ilegalidade, por viverem em espaços públicos, não podem sofrer com o impedimento para serem considerados habitantes titulares do direito à cidade.

Além da população em situação de rua, que pode estar nessa condição, se enquadram também as pessoas que são trabalhadores informais como ambulantes, catadores de resíduos, moradores de assentamentos precários informais, como favelas, cortiços, bairros populares, etc. 
A Nova Agenda Urbana na parte que versa sobre a chamada de ação (Parágrafo 20) deixa claro que essas pessoas devem ter uma particular atenção por serem pessoas que sofrem discriminação. Senão, vejamos.

Reconhecemos a necessidade de conferir particular atenção ao enfrentamento das múltiplas formas de discriminação enfrentadas por, entre outros, mulheres e meninas, crianças e jovens, pessoas com deficiência, pessoas vivendo com HIV/AIDS, idosos, povos indígenas e comunidades locais, moradores de favelas e assentamentos informais, pessoas sem-teto, trabalhadores, pequenos produtores rurais $\mathrm{e}$ pescadores artesanais, refugiados, retornados, deslocados internos e migrantes, independentemente de sua condição migratória (IDEM, p. 9).

Com base no direito fundamental de que nenhuma pessoa pode sofrer qualquer tipo de discriminação e no princípio das funções sociais da cidade, os habitantes na condição de moradores de rua que se encontram em situação de marginalidade e vulnerabilidade não podem ser excluídos da condição de cidadania e, portanto, não podem ser excluídos da condição de habitantes quanto à titularidade do direito à cidade.

\section{OS ESPAÇOS PÚBLICOS COMO COMPONENTES DO DIREITO À CIDADE}

\subsection{DOS COMPONENTES DO DIREITO À CIDADE}

Ao fazermos a leitura da compreensão do direito à cidade no Estatuto da Cidade e no seu tratamento na Nova Agenda Urbana, nos parágrafos 11 a 13 que o Brasil adotou e, portanto, tem compromissos com a sua implementação, podemos considerar como componentes desse direito os seguintes:

Uma cidade livre de discriminação baseada no sexo, idade, estado de saúde, renda, nacionalidade, etnia, condição migratória, ou orientação política, religiosa ou sexual.

Uma cidade com cidadania inclusiva onde cada habitante, seja ele permanente ou transitório, é considerado um cidadão e concede direitos iguais; por exemplo, as mulheres, as pessoas que vivem na pobreza ou em situação de risco ambiental, 
trabalhadores da economia informal, grupos étnicos e religiosos, pessoas LGBT, a forma diferente abled, crianças, jovens, idosos, migrantes, refugiados, moradores de rua, vítimas da violência e os povos indígenas.

Uma cidade com maior participação política na definição, implementação, monitoramento e orçamentação das políticas urbanas e de ordenamento do território, com o propósito de reforçar a transparência, a eficácia e a inclusão da diversidade de habitantes e suas organizações.

Uma cidade com as suas funções sociais que garantem o acesso equitativo de todos à habitação, bens, serviços e oportunidades urbanas, sobretudo às mulheres e outros grupos marginalizados; um ambiente que prioriza o interesse público coletivamente definido, garantindo um uso socialmente justo e ambientalmente equilibrado dos espaços urbanos e rurais.

Uma cidade com espaços públicos de qualidade que favorece a interação social e participação política, fornece as expressões socioculturais, integra a diversidade e promove a coesão social; um município onde os espaços públicos contribuem para a construção de cidades mais seguras e satisfazem as necessidades dos habitantes.

Uma cidade com igualdade de gênero que adquire todas as medidas necessárias para combater qualquer tipo de discriminação contra as mulheres, homens, e pessoas LGBT em termos políticos, sociais, económicos e culturais; uma cidade que adota todas as medidas apropriadas, a fim de garantir o pleno desenvolvimento das mulheres e, ainda a igualdade no exercício e no cumprimento dos direitos humanos fundamentais e uma vida livre de violência.

Uma cidade com diversidade cultural, que respeita, protege e promove os diversos meios de vida, costumes, memória, identidades, expressões e práticas culturais e artísticas dos seus habitantes. Exige respeitar e valorizar todas as religiões, etnias, línguas, culturas e costumes. Que apoia as diversas formas artísticas (música, dança, pinturas, grafites, esculturas, etc) como meio de liberar o potencial social e a criatividade dos habitantes, em especial dos jovens, e construir comunidades pacíficas 
e solidárias, bem como incentivar e fomentar a recreação e o lazer como parte de uma vida plena.

Uma cidade com economias inclusivas, que assegura o acesso aos meios de subsistência e trabalho decente a cada habitante, bem como integra outras economias, tais como a economia solidária, consumo colaborativo, economia circular, reconhecendo também o papel das mulheres na economia do cuidado.

Uma cidade como um sistema de assentamento e ecossistema comum, que respeite os vínculos rural-urbano, e proteja a biodiversidade, habitats naturais e ecossistemas circundantes, e suporte cidades-regiões, a cooperação cidade-cidade, e a conectividade.

\subsection{DOS ESPAÇOS PÚBLICOS}

Os espaços públicos são todos os lugares de propriedade pública ou de uso público, acessível e desfrutável por todos sem necessidade de pagamento e sem fins lucrativos. Isso inclui ruas, espaços abertos e instalações públicas.

Os espaços públicos devem ser vistos como áreas multifuncionais para a interação social, o intercâmbio econômico e a expressão cultural entre uma grande diversidade de pessoas e devem ser desenhados e administrados para garantir o desenvolvimento humano, a construção de sociedades pacíficas e democráticas e a promoção da diversidade cultural.

São os espaços públicos e as ruas que definem o caráter de uma cidade, bem como suas praças e avenidas, jardins e parques moldam a sua imagem. A matriz que conecta as ruas e os espaços públicos formam o esqueleto da cidade, onde tudo mais se encontra.

O espaço público assume muitas formas espaciais, incluindo parques, ruas, calçadas e caminhos que ligam parquinhos de recreação, mercados, mas também espaços entre prédios ou acostamentos, que muitas vezes são espaços importantes para os pobres urbanos, e em muitos contextos as praias também são espaços públicos. 
Isso não significa que todos os espaços públicos são "espaços abertos" - uma biblioteca, uma escola ou outras instalações públicas também são espaços públicos.

Assim, o espaço público constitui o cenário para uma panóplia de atividades - as festividades cerimoniais da cidade multicultural, as atividades da cidade comercial, o movimento de bens e pessoas, a provisão de infraestrutura ou o ambiente para a vida comunitária e os meios de subsistência dos pobres urbanos - tais como vendedores de rua ou catadores de materiais recicláveis.

Com base no Objetivo de Desenvolvimento Urbano 11 (Cidades Sustentáveis) da Agenda 2030, a Agência ONU-Habitat está propondo um conjunto de metas para o total de solo urbano destinado a ruas e espaços públicos para assegurar fundações adequadas para a cidade.

A proposta de objetivo/meta de espaço público sugerida é que $45 \%$ da terra deve ser alocada para ruas e espaço público. Isso pode ser dividido em $30 \%$ para ruas e calçadas e 15\% para espaços abertos, espaços verdes e instalações públicas.

A meta para conectividade de ruas é entre 80-120 cruzamentos por quilômetro quadrado. A um nível ótimo de 100 cruzamentos por $\mathrm{km}^{2}$, com cada rua tendo uma largura média de $15 \mathrm{~m}$, as ruas de uma cidade ocupariam cerca de $28 \%$ da área total. Isso também deve ser complementado por um objetivo qualitativo que avalie a acessibilidade, o uso e a segurança, entre outros aspectos.

Os espaços públicos devem cumprir sua função social segundo a qual não se pode estabelecer formas de discriminação pela condição social dos habitantes, como a população de rua. Os espaços públicos devem ser gratuitos e estar livres de barreiras físicas, jurídicas e arquitetônicas que impeçam a presença de pessoas moradores de rua e pessoas de baixa renda, que dificultem a circulação de pessoas com mobilidade reduzida em razão do exercício pleno de seus direitos e liberdades.

Importante destacar que com base na gestão democrática das cidades, é fundamental que os espaços públicos tenham uma gestão comunitária que favoreça a mediação e 
a solução dos conflitos para o uso e ocupação desses espaços e a busca por soluções para a situação da população moradora de rua.

\section{ESPAÇOS PÚBLICOS E POPULAÇÃO EM SITUAÇÃO DE RUA}

Numa manhã de domingo, no epicentro da região mais conturbada da cidade de São Paulo, um mar de gente disputa cada centímetro da via pública na Alameda Dino Bueno, na Cracolândia. É um exército de desvalidos que ocupa o espaço público para atingir o prazer imediato proporcionado pelas drogas, particularmente o crack, ou, simplesmente, manter-se em estado de entorpecimento e continuar desconectado da realidade que não oferece nenhuma perspectiva viável para a maioria dos que estão ali.

Nesta região, encravada no centro da maior cidade do país, o espaço público é sinônimo de exclusão para todos que vivem no local. De um lado, os moradores ou proprietários de imóveis não podem usufruir adequadamente da via pública devido ao incômodo do "fluxo"[5]. E, do outro, a multidão que vive em situação de rua é lançada à própria sorte, sem assistência adequada do Poder Público.

Na concepção clássica, o espaço público é o lugar da cidade onde o Estado deve concentrar todos os esforços para garantir o direito de usufruir do patrimônio comum de todos e de utilizar o seu mobiliário urbano.

O espaço público é o ambiente mais democrático da cidade, pois tem a função social de permitir o intercâmbio heterogêneo em tempo, espaço, idade, nacionalidade e diversidade. É, portanto, um lugar destinado ao uso social típico da vida urbana, lugar de convívio e interação.

A rua, por sua vez, constitui um espaço público que agrega aos demais, pois dá conformidade à estrutura urbana. É pela rua que os habitantes da cidade transitam, observam, conhecem e interagem uns com os outros e com os elementos ali presentes. 
Neste sentido, um dos fundamentos do direito à cidade é assegurar um ambiente urbano digno para todos os seus frequentadores, sejam moradores locais, visitantes, proprietários ou locatários, nacionais ou estrangeiros, através da divisão de todos os benefícios e problemas do ambiente urbano de forma igual.

No caso da Cracolândia, o que se percebe é que os espaços públicos perderam a sua finalidade original. Atualmente eles estão desprovidos de qualquer possibilidade de uso, interação ou compartilhamento seguro para quem habita nas imediações ou transita diariamente pela região.

\subsection{ORIGEM DA POPULAÇÃO EM SITUAÇÃO DE RUA}

Para entender a complexa relação entre espaços públicos e população em situação de rua, é importante visualizar a origem desse ajuntamento humano que ocupa, indevidamente, as vias públicas, e compreender que ele não está ali por vontade própria.

Para Maria Lúcia Lopes da Silva (2009, p. 130), a população em situação de rua é caracterizada como um fenômeno social no contexto da produção de uma superpopulação relativa ou exército industrial de reserva para atender às necessidades de expansão do capital.

Segundo a doutora em Política Social pela Universidade de Brasília (2009, p. 91) essa população é uma síntese de múltiplos fatores econômicos e sociais, cujas características a tornam um elemento de grande relevância na composição da pobreza nas sociedades capitalistas.

A primeira premissa estabelecida pela autora é a de que a população em situação de rua não é diretamente responsável pela situação desafortunada em que se encontra. É "uma condição não escolhida pelos que nela se encontram, mas que nela foram colocados" (IDEM, p.137). 
A origem de tal fenômeno social remonta ao surgimento das cidades pré-industriais da Europa, momento em que a pobreza passou a compor o cenário da vida urbana em várias partes do mundo.

No caso específico da população em situação de rua no Brasil, essa realidade social está inserida no contexto das mudanças ocorridas no mundo do trabalho e outras transformações promovidas pelo capitalismo contemporâneo.

Condições histórico-estruturais deram origem ao fenômeno do pauperismo, ao qual se vincula o que hoje se denomina população em situação de rua. Tem como base a expropriação dos produtores rurais e camponeses e sua transformação em assalariados, no contexto da chamada acumulação primitiva e da indústria nascente (SILVA, 2009, p.96).

Segundo a especialista (2009), o fenômeno surgiu no seio do pauperismo generalizado na Europa Ocidental do final do século XVIII, compondo as condições históricas necessárias à produção capitalista, entre elas a formação do exército de reserva, descrito por Marx[6] como condição para a perpetuação do sistema capitalista, "aquela parcela da classe trabalhadora que perdeu a condição de sua existência, a venda da força de trabalho, e vegeta na base da caridade pública" (IDEM, p. 97).

Além da questão histórica, há uma multiplicidade de fatores que caracterizam o fenômeno da população em situação de rua, ou seja, não é um aspecto único e determinante que conduz uma pessoa à condição de vulnerabilidade na rua, mas vários deles.

Há fatores estruturais como ausência de moradia, inexistência de trabalho e renda, mudanças econômicas e institucionais de forte impacto social que empurram um significativo contingente para as ruas.

Também é visível a influência de fatores biográficos, aqueles ligados à história de vida de cada indivíduo, tendo peso expressivo as rupturas dos vínculos familiares, doenças mentais, consumo patológico de álcool e outras drogas, infortúnios pessoais, morte 
de todos os componentes da família, roubo de todos os bens, fuga do país de origem, para citar somente alguns.

Menos comum no Brasil, mas não inexistente, o fenômeno social também pode ser determinado por fatores da natureza ou desastres de massas, como terremotos, inundações, deslizamentos de terra em encostas, que deixam as vítimas em total estado de desassistência social.

Porém dentre todos esses fatores, a literatura destaca como mais significativas as rupturas dos vínculos familiares e comunitários, a inexistência de trabalho regular e a ausência ou insuficiência de renda, além do uso frequente de álcool e outras drogas, bem como problemas atinentes às situações de desabrigo (IBDEM, p.105).

O segundo aspecto decorre da falta de alcance das políticas públicas universais que são elaboradas originalmente pelo Estado para atingir a população como um todo, mas que, no caso da população em situação de rua, não têm efeito residual, ou seja, o grupo de vulneráveis não é atingido por tais políticas públicas.

Desse modo, o Estado sempre funcionou de forma a tratar os problemas da população em geral de maneira homogênea, elaborando políticas de atendimento a grupos ou classes relativamente homogêneas, mas, no caso da população em situação de rua, é imperioso tratar as demandas desse público de forma particular.

Especialistas da área de assistência social recomendam a elaboração de estratégias especiais para o enfrentamento dos problemas vividos pelos moradores em situação de rua, sendo necessário abolir as políticas universais e investir em políticas residuais, com especial atenção às situações particulares deste público social.

Logo, este fenômeno constitui a expressão mais acentuada da desigualdade social, que materializa e dá visibilidade à violência do capitalismo sobre o ser humano. Este é completamente despojado dos meios de produzir riqueza para uso próprio, sendo submetido a níveis extremos de degradação de vida.

Por essa razão, as populações em situação de rua se concentram majoritariamente nos grandes centros urbanos do país, haja vista que nestes locais a circulação do 
capital ocorre com maior intensidade. Essa condição gera alternativas de trabalho para subsistência diária, ainda que precárias, às pessoas que fazem da rua espaço de moradia e subsistência.

Essa lógica da subsistência, gerada pela exclusão do capitalismo, promove uma mobilidade de autogeração de trabalho em que pobres produzem para pobres, gerando uma economia da pobreza, como atesta Patrícia Rodriguez Alomá.

En el contexto neoliberal excluyente, quedan marginados del mercado laboral una gran cantidad de sectores sociales, lo cual supone, según Pérez Sainz, que está modalidad de autogeneración de empleo está signada por lógicas de subsistencia, de ahí su denominación como economía de la pobreza. Se trata de pobres produciendo para pobres (ALOMÁ, 2013).

Este quadro de adensamento torna-se visível porque nos grandes centros urbanos há maior disponibilidade de materiais recicláveis que diariamente são descartados como lixo e que são reaproveitados por catadores de materiais recicláveis.

Isso ocorre porque os grandes centros concentram várias atividades econômicas comerciais, bancárias e de serviços que atraem muita gente. Segundo Silva (2009, p.117)

são áreas preferidas pelas pessoas em situação de rua pela facilidade de receber doações ou obter rendimentos realizando atividades econômicas informais, como venda de mercadorias de baixo valor comercial, guarda de carro, serviços de engraxates, revenda de ingressos para acesso a atividades culturais e/ou esportivas, etc.

Outro fator de atração para a população em situação de rua nos grandes centros urbanos é a oferta de infraestrutura. Apesar de limitadas e insuficientes, as grandes cidades são dotadas de infraestrutura mais adequada para 0 atendimento das necessidades básicas de alimentação, abrigo, higiene e saúde.

Ainda como fator determinante da exclusão da população em situação de rua temos o preconceito como marca do grau de dignidade e valor moral atribuído pela sociedade às pessoas atingidas por esse fenômeno. Nesse sentido é comum ouvir denominações pejorativas e humilhações frequentes. 
É muito comum que as pessoas em situação de rua sejam responsabilizadas pela situação em que se encontram por suas 'imperfeições' ou 'falhas' de caráter. Muitas vezes também são tratadas como uma ameaça à comunidade (SILVA, 2009, p.120).

Borin (2003), considera que os moradores em situação de rua são fortemente estigmatizados pelos cidadãos da cidade, despertando medo, nojo e descaso. Esse tipo de reação, segundo Silva (2009), resulta em práticas higienistas, direcionadas para camuflar o fenômeno social da população em situação de rua, mediante massacres, extermínios ou recolhimento forçado dessas pessoas das ruas, práticas que continuam presentes nos tempos atuais, nos grandes centros urbanos do País, até mesmo conduzidas por órgãos do Poder Público.

De igual modo há outra importante razão que explica o fenômeno da população em situação de rua, que são as particularidades vinculadas ao território em que se manifesta.

Trata-se de um fenômeno que tem características gerais, mas possui particularidades vinculadas ao território em que se manifesta. Essas particularidades são decorrentes de hábitos, valores e características socioeconômicas, culturais e geográficas predominantes no território.

Tais especificidades se refletem no perfil socioeconômico, no tempo de permanência nas ruas, e nas estratégias de subsistência utilizadas pelas pessoas em situação de rua.

Outro aspecto, não menos importante, é a tendência à naturalização do fenômeno em razão da inexistência de políticas sociais capazes de reduzir a pobreza e as desigualdades sociais na perspectiva de ampliar a cidadania, de garantir cobertura às pessoas em situação de rua, bem como, devido à insuficiência (ou inexistência) de dados e informações científicas sobre o fenômeno que comumente é visto como um processo natural da sociedade moderna. Em outras palavras, o fenômeno da população em situação de rua é visto como um processo natural de degradação humana, como consequência de uma escolha individual. 
É, pois, uma tendência que atribui aos indivíduos a responsabilidade pela situação em que se encontram, isentando a sociedade capitalista da produção e reprodução do fenômeno e o Estado da responsabilidade de enfrentá-lo (SILVA, 2009, p.122).

Nesse contexto, existem algumas características gerais da população em situação de rua. É uma população bastante heterogênea, formada por pessoas de origens, interesses, vinculações sociais e perfis socioeconômicos completamente diversificados. Como diz Silva (2009, p. 123) "não há um único perfil da população de rua, há perfis; não é um bloco homogêneo de pessoas, são populações".

Segundo dados do Cadastro Único de Assistência Social (Brasil, 2020), até março deste ano as prefeituras registraram cerca de 150 mil pessoas em situação de rua em todo o Brasil. Desse contingente, perto de 25 mil encontram-se na cidade de São Paulo.

Para a totalidade dessa população de miseráveis a inexistência de moradias convencionais e regulares faz com que os espaços públicos, notadamente as ruas, sejam usados como espaço de moradia e sustento por contingência temporária ou de forma permanente.

Neste cenário, a falta de moradia constitui um dos problemas crônicos para a população em situação de rua. O último censo realizado pela Prefeitura de São Paulo (SMADS, 2019) mostrou que entre as pessoas sem lugar para morar na capital paulista, 11,7 mil dormem em abrigos e 12,6 mil estão em calçadas ou sob viadutos.

Ainda segundo o senso, $69,35 \%$ da população é formada por negros. Os indígenas somam $1,7 \%$ e os brancos, $28 \%$. A maioria dos moradores em situação de rua (85\%) são homens, e, em relação à identidade de gênero, 386 pessoas se declararam transsexuais.

Para atender a essa multiplicidade de perfis é urgente a adoção de políticas públicas específicas para a população em situação de rua. 


\subsection{A POLÍTICA DE ASSISTÊNCIA SOCIAL NA CIDADE DE SÃO PAULO}

$\mathrm{Na}$ cidade de São Paulo a lei 12.316/1997 dispõe expressamente sobre a obrigatoriedade do poder público municipal de prestar atendimento à população em situação de rua. Somente quatro anos depois, a lei foi regulamentada pela prefeitura, através do Decreto № 40.232, de 2 de janeiro de 2001, que sofreu modificações ao longo do tempo até ser totalmente revogado em março de 2013 pelo Decreto no 53.795, de 25 de março de 2013.

Dentro desse escopo de atendimento, a Prefeitura de São Paulo disponibiliza alguns serviços voltados para a população em situação de rua, como os Centros de Referência Especializados para População em Situação de Rua, instituições de acolhimento, Centros de Referência Especializados de Assistência Social (CREAS) e os Centros de Referência de Assistência Social (CRAS).

Todavia, essas iniciativas, apesar de necessárias, têm se mostrado insuficientes para combater efetivamente o fenômeno da população em situação de rua na cidade de São Paulo.

A partir de agora faremos uma descrição da realidade encontrada na região conhecida como Cracolândia em atendimentos realizados in loco acompanhando grupos de voluntários que atuam na região.

Entre a população em situação de rua, é unânime o entendimento de que não há oferta de espaços públicos adequados para o atendimento das demandas específicas desse público, sendo o principal deles a ausência de oferta de moradia.

Essa população não tem onde dormir e, por essa razão, transforma a via pública em acampamento a céu aberto, local em que o consumo de drogas é "tolerado" pelo Poder Público em nome da política de assistência social instituída no município. O que, na prática, serve tão somente para camuflar a realidade porque não se combate nem a causa do problema (o que leva as pessoas para a situação de rua) e muito 
menos o tráfico de drogas que impera na região e que mantém as pessoas escravizadas como zumbis circulando pelas ruas.

Sendo assim, uma forma de fazer frente ao fenômeno social da população em situação de rua seria investir na oferta prioritária de moradia para quem está jogado à própria sorte no fluxo da Cracolândia.

Essa medida não se confunde com a política de abrigamento que já é praticada pela Secretaria Municipal de Assistência e Desenvolvimento Social, visto que há obstáculos que afastam a população em situação de rua desses locais de apoio, bem como o problema da limitação de vagas.

Trata-se de investimento em moradia individual ou familiar para combater diretamente o problema em todas as suas raízes, viabilizando tratamento médico e apoio multiprofissional especializado para as demandas específicas caso a caso.

Claramente, não há interesse do Poder Público em fixar essa população no território da Luz, na região central de São Paulo, uma vez que há a prevalência de interesses econômicos de grupos ligados ao setor imobiliário, no sentido de revitalizar o centro de São Paulo e atrair para o local classes sociais mais abastadas, considerando o potencial turístico e histórico da região.

Dessa forma, o Poder Público municipal realiza ações de apoio à população em situação de rua em espaços distantes deste território, com a intenção de que esse contingente migre para outras regiões da cidade, preferencialmente longe da região central.

Outro problema crucial é a falta de empatia. Quem se encontra em situação de vulnerabilidade é mal visto pela sociedade como um todo, pois está despreza e fecha os olhos para a realidade atroz que atinge esse público marginalizado. Os moradores em situação de rua não são aceitos nos espaços públicos. A presença deles é um incômodo, um fardo para a sociedade. 
Por isso, se escondem nas ruas, em espaços obscuros, em praças abandonadas e com pouca oferta de serviços públicos ou recorrem aos centros de acolhida, ONGs, igrejas, banheiros sociais, etc.

Faltam espaços públicos adequados que sirvam à recuperação da população em situação de rua ou que, pelo menos, permita um certo alento ante à miséria em que vivem.

No tocante à região da Cracolândia um problema gritante e que fere o princípio constitucional da dignidade humana é a falta de banheiros públicos. Os que existem no projeto Redenção, ligados à Prefeitura de São Paulo, são insuficientes para atender toda a demanda da região. Dessa forma, sem acesso a este serviço fundamental, muitos moradores em situação de rua fazem as suas necessidades fisiológicas na via pública, transformando as sarjetas em repositórios de esgoto a céu aberto.

Neste período de pandemia, por exemplo, foram instaladas algumas torneiras em praças e alguns banheiros públicos foram abertos na cidade, mas nenhuma dessas iniciativas foi implementada na região da Cracolândia.

Durante os meses de maior incidência da pandemia de Covid-19, em ações de rua realizadas por voluntários de uma instituição de caridade ligada à Paróquia Sagrado Coração de Jesus, no bairro de Campos Elíseos, foi possível observar o tamanho da carência dessa população em relação a espaços públicos acessíveis.

De março a junho de 2020, o grupo forneceu refeições para os moradores em situação de rua. Os beneficiários que se apresentavam para receber a refeição, antes, lavavam as mãos com água e sabão, como medida de prevenção ao novo coronavírus, usando uma mangueira improvisada na calçada da via pública. E muitos deles suplicavam para lavar a cabeça com água e detergente líquido, numa clara demonstração da necessidade por cuidados de higiene pessoal.

Com relação aos centros de acolhida, mantidos pelo Poder Público municipal, há poucas vagas para atender à crescente demanda da população em situação de rua e 
há vagas igualmente limitadas para o acolhimento de pessoas com comorbidades e que necessitam de cuidados especiais.

Além da falta de vagas, os moradores em situação de rua reclamam bastante da forma como esses espaços são administrados por organizações sociais (associações ou fundações) ou por organizações da sociedade civil de interesse público - OSCIP's.

Essas entidades são vinculadas ao Poder Público por meio de contrato de gestão, em regime de parceria, para que possam prestar serviços públicos essenciais (serviços sociais) em substituição ao primeiro, originalmente responsável por tais serviços.

Em razão de problemas na gestão desses espaços públicos, muitos moradores em situação de vulnerabilidade preferem dormir na rua a submeter-se às regras dos centros de acolhida, que, por exemplo, não admitem a entrada de animais de estimação e, por isso, um grande número de assistidos ficam na rua por causa do cachorro, que, para a maioria, é o seu único companheiro.

Outro fator de afastamento dos moradores em situação de rua é que comumente eles reclamam da infestação desses locais por muquiranas (piolhos) e outros ectoparasitas. Os relatos são de que quando dormem nos centros de acolhida os assistidos são infectados por parasitas.

Ademais, os horários de entrada e saída dos centros de acolhida, bem como a localização dos espaços públicos desestimulam a sua procura por serem incompatíveis com a realidade da maioria dos assistidos.

As vagas normalmente são distribuídas a tarde e sempre para pernoites. A oferta de vaga fixa é bem difícil de conseguir. O problema é que a maioria tem hábitos noturnos, trabalham na coleta de recicláveis durante a noite e dorme tarde, em horários em que a entrada nos abrigos já não é permitida.

Desse modo, os abrigos localizados próximos à área central de São Paulo sempre ficam lotados, já as vagas oferecidas para abrigos distantes do centro são recusadas. 
Outra necessidade premente é a falta de guarda-volumes para que os integrantes desse numeroso grupo populacional possam depositar objetos pessoais, como roupas, materiais de higiene pessoal e documentos em um local seguro, sem o risco de extraviar como é comum acontecer nas ruas.

Do total de 24.344 pessoas que vivem em situação de rua na cidade de São Paulo (SMADS, 2019), pouco mais da metade (15.905 pessoas) dorme em calçadas ou abrigos públicos. Segundo o censo, 11,7 mil dormem em abrigos e 12,6 mil estão em calçadas ou sob viadutos, ou seja, a maioria do contingente de moradores em situação de rua não é atendida pelas políticas públicas do Poder Público municipal.

O censo realizado pela Prefeitura de São Paulo foi bastante criticado pelos movimentos de defesa da população em situação de rua para que os números do levantamento estariam subnotificados e seriam bem maiores do que os dados oficiais.

De fato, ao circular pela região central de São Paulo, observa-se um maior número de pessoas vivendo em situação sub-humana. Pessoas que, por causa da crise econômica causada pela pandemia de Covid-19, perderam seus empregos, renda e passaram a vir para a rua em busca de doações de comida e mantimentos. São indivíduos que não vivem na rua, mas estão circunstancialmente na rua por alguma situação específica e temporária.

Esse maior adensamento populacional foi verificado nas imediações do Pátio do Colégio, Largo São Francisco, Praça Patriarca, Teatro Municipal e Praça da Sé, para citar apenas alguns pontos da região central, que receberam centenas de novas barracas que abrigam famílias inteiras.

Neste caso, os novos moradores em situação de rua são vítimas de um processo de pauperização crescente motivado pela perda de emprego e de renda ao longo do tempo, que os empurra para a linha da extrema pobreza por causa da pandemia. 


\section{CONSIDERAÇÕES FINAIS}

Como demonstrado, o direito à cidade é a nova baliza para o enfrentamento do fenômeno social caracterizado pela população em situação de rua. Ele oferece um vasto instrumental para a elaboração de políticas públicas destinadas à mitigação da pobreza, exclusão social e dos danos ambientais, que exigem ações decisivas e novas prioridades políticas nacionais, regionais e dos governos locais.

Tudo isso corrobora a certeza de que os moradores em situação de rua também são detentores do direito à cidade e devem ser respeitados enquanto sujeitos desses direitos que devem ser assegurados pelo Poder Público.

Destarte, estamos falando de um grupo populacional que é dolorosamente afetado pela miséria e pela extrema pobreza. A realidade das pessoas que sobrevivem nas ruas é marcada pela completa escassez. E a maior demonstração disso é a perda da dignidade humana, pois ao habitarem os espaços públicos se submetem a condições sub-humanas.

Os espaços públicos, enquanto locus de convivência e de fruição do patrimônio comum não são sustentáveis e muito menos acessíveis à população numa realidade de completa exclusão social.

Para que os cidadãos utilizem o mobiliário urbano, exerçam o direito de ir e vir, circulem e caminhem com segurança pelas ruas é preciso que o Estado propicie condições mínimas para o exercício desses direitos fundamentais.

O espaço público nas regiões marcadas pelo fenômeno social da população em situação de rua precisa ser repensado, revitalizado por políticas públicas específicas, e não generalizantes, que priorizem a assistência integral aos moradores em situação de vulnerabilidade absoluta.

O Estado, em caráter emergencial, deve prover a esse público alimentação, atendimento médico, psicológico e psiquiátrico, além de um programa de moradia individual em habitações convencionais ou em hotéis da região central para que essa 
população tenha a oportunidade de sonhar com um futuro livre da dependência química e da miséria das ruas.

Somente dessa forma é que podemos imaginar a região hoje conhecida pejorativamente como Cracolândia como um local de atração turística e histórica para a cidade.

Neste caso, a intervenção cirúrgica do Estado, com políticas públicas efetivas, poderia devolver ao público as fachadas centenárias das casas dos Campos Elíseos. E devolveria a rua ao povo enquanto local de passagem, de intercâmbio heterogêneo como lugar destinado ao uso social típico da vida urbana, lugar de convívio e interação.

Em última análise, é repensar a cidade para todos, assegurando um ambiente urbano digno para todos os seus frequentadores, sejam moradores com residência fixa ou transeuntes, visitantes e turistas, e todos os egressos da população em situação de rua que poderiam habitar a região de forma regular e digna.

$\mathrm{O}$ direito à cidade requer um olhar diferenciado para o outro. Exige o exercício da empatia, sem ignorar ou desprezar o sofrimento humano, e as agruras da cidade, geradas pela desigualdade social e econômica.

\section{REFERÊNCIAS BIBLIOGRÁFICAS}

ALOMÁ, Patricia Rodriguez. El Espacio Público, ese protagonista de la ciudad. Plataforma Urbana. Publicado em 14.Nov.2013. Disponível em: https://www.plataformaurbana.cl/archive/2013/11/14/el-espacio-publico-eseprotagonista-de-la-ciudad/?utm_medium=website\&utm_source=archdaily.com.br. Acesso em 05.10.2020.

BOBBIO, Noberto. Direito do Homem e Sociedade - Era dos Direitos. Editora Campus, Rio de Janeiro, 1996. 
BORIN, Maria do Espírito Santo. Desigualdades e rupturas sociais na metrópole. Os moradores de rua em São Paulo. Tese de Doutorado em Ciências Sociais. Pontifícia Universidade Católica de São Paulo, São Paulo, 2003.

BRASIL, Ministério da Cidadania. Portaria traça diretrizes para proteger a população em situação de rua durante a pandemia. Brasília, DF. Publicada em 18.mai.2020. Disponível em: https://www.gov.br/cidadania/pt-br/noticias-econteudos/desenvolvimento-social/noticias-desenvolvimento-social/portaria-tracadiretrizes-para-proteger-a-populacao-em-situacao-de-rua-durante-a-pandemia. Acesso em: 27.set.2020.

NAÇÕES UNIDAS. Convenção para a Salvaguarda do Patrimônio Cultural Imaterial. $\quad 2003 . \quad$ Paris, Disponível em: http://portal.jphan.gov.br/uploads/ckfinder/arquivos/ConvencaoSalvaguarda.pdf. Acesso em: 20.set.2020.

NAÇÕES UNIDAS. Declaração sobre o Direito ao Desenvolvimento - 1986. Adotada pela Resolução 41/128 da Assembleia das Nações Unidas, 1986. Biblioteca Virtual de Direitos Humanos - Universidade de São Paulo. Sem data de publicação. Disponível em: http://www.direitoshumanos.usp.br/index.php/Direito-aoDesenvolvimento/declaracao-sobre-o-direito-ao-desenvolvimento.html. Acesso em: 20.set.2020.

NAÇÕES UNIDAS. Nova Agenda Urbana. Declaração de Quito sobre Cidades e Assentamentos Urbanos para todos. Quito, 2016. Disponível em: http://habitat3.org/wp-content/uploads/NUA-Portuguese-Brazil.pdf. Acesso em: 20.set.2020.

PLATAFORMA GLOBAL DIREITO À CIDADE. Cities for dignity, not for profit. Disponível em: https://www.right2city.org/. Acesso em: 20.set.2020.

RIGHT TO THE CITY AGENDA. For the Implementation of the 2030 Agenda for Sustainable Development and the New Urban Agenda 2018. Disponível em: http://polis.org.br/publicacoes/right-to-the-city-agenda-for-the-implementation-of- 
the-2030-agenda-for-sustainable-development-and-the-new-urban-agenda/. Acesso em: 19.set.2020.

RIO 92. Tratado sobre a Questão Urbana por Cidades Vilas e Povoados Justos Democráticos e Sustentáveis. Disponível em: https://docplayer.com.br/23279786Tratados-sobre-a-questao-urbana-por-cidades-vilas-e-povoados-justosdemocraticos-e-sustentaveis-preambulo.html. Acesso em: 19.set.2020.

SÃO PAULO. Decreto o 40.232, de 2 de janeiro de 2001. Regulamenta a Lei no 12.316, de 16 de abril de 1997, que dispõe sobre a obrigatoriedade do Poder Público Municipal a prestar atendimento à população de rua da Cidade de São Paulo, e dá outras providências. São Paulo, SP. Publicado em 03.jan.2001. Disponível em: http://legislacao.prefeitura.sp.gov.br/leis/decreto-40232-de-2-dejaneiro-de-2001. Acesso em 15.set.2020.

SÃO PAULO. Decreto № 43.277, de 29 de maio de 2003. Institui o Conselho de Monitoramento da Política de Direitos das Pessoas em Situação de Rua na Cidade de São Paulo. São Paulo, SP. Publicado em 30.mai.2003. Disponível em: http://legislacao.prefeitura.sp.gov.br/leis/decreto-43277-de-29-de-maio-de-2003. Acesso em 15.set.2020.

SÃO PAULO. Decreto no 53.795, de 25 de março de 2013. Institui o Comitê Intersetorial da Política Municipal para a População em Situação de Rua - Comitê PopRua. São Paulo, SP. Publicado em 26.jun.2013. Disponível em: http://legislacao.prefeitura.sp.gov.br/leis/decreto-53795-de-25-de-marco-de-2013. Acesso em: 15.set.2020.

SÃO PAULO. Decreto no 55.874, de 29 de janeiro de 2015. Institui o Programa TransCidadania, destinado à promoção da cidadania de travestis e transexuais em situação de vulnerabilidade social. São Paulo, SP. Publicado em 30.jan.2015. Disponível em: http://legislacao.prefeitura.sp.gov.br/leis/decreto-55874-de-29-dejaneiro-de-2015. Acesso em: 15.set.2020. 
SÃO PAULO. Lei nº 12.316, de 16 de abril de 1997. Dispõe sobre a obrigatoriedade do poder público municipal a prestar atendimento à população de rua na Cidade de São Paulo. São Paulo, SP. Publicada em 26.abr.1997. Disponível em: http://legislacao.prefeitura.sp.gov.br/leis/lei-12316-de-16-de-abril-de-1997. Acesso em 20.set.2020.

SILVA, M. L. L. da. Trabalho e população em situação de rua no Brasil. São Paulo: Cortez, 2009.

SMADS- Secretaria Municipal de Assistência e Desenvolvimento Social. Censo da População em Situação de Rua 2019. São Paulo, SP. Publicado em 31.jan.2020. Disponível em: https://www.prefeitura.sp.gov.br/cidade/secretarias/assistencia_social/observatorio_s ocial/pesquisas/index.php?p=18626. Acesso em: 20.set.2020.

SNOW, D.; ANDERSON, L. Desafortunados: um estudo sobre o povo da rua. Petrópolis: Vozes, 1998.

SPOSATI, A. Vida urbana e gestão da pobreza. São Paulo: Cortez, 1988.

\section{APÊNDICE - REFERÊNCIAS DE NOTA DE RODAPÉ}

3. Ver Nova Agenda Urbana: http://habitat3.org/wp-content/uploads/NUA-PortugueseBrazil.pdf

4. Ver plano diretor Lei no 16.050, de 31 de julho de2014.. https://gestaourbana.prefeitura.sp.gov.br/arquivos/PDE-Suplemento DOC/PDE_SUPLEMENTO-DOC.pdf

5. Fluxo é o local onde comumente ocorre a maior concentração de pessoas atraídas pela comercialização e consumo de entorpecentes na via pública. O espaço público é usado para o fluxo das drogas. 
6. O exército de reserva corresponde à força de trabalho que excede as necessidades da produção. Para o bom funcionamento do sistema de produção capitalista e garantir o processo de acumulação, é necessário que parte da população ativa esteja permanentemente desempregada. Esse contingente de desempregados atua, segundo a teoria marxista, como um inibidor das reivindicações dos trabalhadores e contribui para o rebaixamento dos salários. Enciclopédia Wikipédia. Disponível em: https://pt.wikipedia.org/wiki/Ex\%C3\%A9rcito_industrial_de_reserva. Acesso em: 07.10.2020.

Enviado: Outubro, 2020.

Aprovado: Novembro, 2020. 